\title{
Should the on-call psychiatrist be residential?
}

\author{
Andrew Lawrie, Marc Serfaty and Chris Smith
}

\begin{abstract}
The need for poychiatrists to be reaidential when on call is questionable. To determine whether becoming nonresidentilal resulted in duty doctors being unable to provide the same quallty of care in dealing with poychiaticic or medical emergencies, a prospective study was corried out logging colls recelved by the duty doctor before and afier fronsition from a residential to a non-residential on-call system. Outcome showed that requiling doctors to be resident did not seem justilied.
\end{abstract}

Junior doctors' working conditions are an area of increasing interest (NHS Management Executive, 1991). An important component is on-call duty. In the authors' experience, being nonresident considerably reduces stress and lessens the burden of on-call duties. This is supported by doctors on call from home having lower stress scores (Schwartz, 1987), while too few hours at home and too many hours at the hospital have been shown to correlate with 'relationship stress' between junior doctors and their partners (Landau, 1986). At the same time the move to community-based units has led to duty doctors having to cover a number of psychiatric units in separate locations and thus be 'off-site'. Many psychiatric units have separate cover for cardiac arrest calls.

The following study, undertaken at St Nicholas' Hospital, Newcastle upon Tyne, examined changes in the quality of emergency care during a shift from a residential to a non-residential oncall system (Nicholls, 1992). St. Nicholas' is a 305 bed Psychiatric Hospital, covering inner city and suburban catchment areas of a population of approximately 250000 . The on-call duties include The Grange, a nine bed community mental health unit, three miles from the main hospital site. A prerequisite of non-residential on-call was that the duty doctor lived within five miles of St. Nicholas' Hospital. Medical cover was provided by the cardiac arrest team based at Newcastle General Hospital (three miles from the main site).

\section{The study}

All out-of-hours calls (5pm-9pm and weekends) which doctors on duty received between 15 th
February and 31st July 1993 (two and a half months residential followed by three months non-residential) were recorded. Two independent raters graded the calls ' $A$ ' to ' $E$ ', defined as follows: ' $A$ ' calls are medical emergencies which are life threatening and require immediate responses for intervention or assessment (e.g. haematemesis, chest pain, fractured neck of femur); ' $B$ ' calls are psychiatric emergencies which require immediate intervention (e.g. acutely disturbed patients requiring medication): 'C' (urgent) calls are those in which a delay in assessment would not adversely affect the wellbeing of the patient; ' $D$ ' calls are inappropriate, for example due to nursing staff error; ' $E$ ' calls are for advice not requiring attendance. Interrater reliability was high (kappa=0.96, $P<0.001$ ). In addition calls were divided into ward types: acute, long-stay well staffed (medical cover $>3$ days per week); long-stay staffed (medical cover $<3$ days per week); and miscellaneous (e.g. general practitioners (GPs), Police). 'A' (medical emergencies) and ' $B$ ' (psychiatric emergencies) calls were further investigated by asking the duty doctor to assess whether the delay in being off site (20 to 30 minutes travel time) significantly affected the outcome and/or caused distress to the patient.

\section{Findings}

Over twice as many days were covered during the residential period and therefore the total number of calls logged is likely to be greater. Absolute numbers of calls are given in the text, however, to compare the residential and non-residential groups, calls were calculated per thousand hours. This adjustment is shown in Table 1.

Over the period of study (181 days), 91 days were investigated: 63 were in the residential period and 28 were non-residential. Ninety days were not recorded. Further analysis showed that it was the same junior doctors who failed to log their calls, and it is therefore unlikely that this would result in selection bias in the types of calls recorded. A total of 282 ward visits were made, 147 in the residential period. 
Table 1. Number of calls per 1000 hours

\begin{tabular}{|c|c|c|c|}
\hline & Type of cell & Realdential & $\begin{array}{l}\text { Non- } \\
\text { realdential }\end{array}$ \\
\hline $\begin{array}{l}\text { 'A' } \\
\text { 'B' } \\
{ }^{\prime} \mathrm{C} \\
\mathrm{D}^{\prime} \\
{ }^{\prime} \mathrm{E}\end{array}$ & $\begin{array}{l}\text { Medical emergency } \\
\text { Psychlatric emergency } \\
\text { Urgent } \\
\text { Inapproprlate } \\
\text { Advice }\end{array}$ & $\begin{array}{r}6 \\
7 \\
109 \\
78 \\
111\end{array}$ & $\begin{array}{r}8 \\
6 \\
112 \\
59 \\
72\end{array}$ \\
\hline Total & & 311 & 257 \\
\hline
\end{tabular}

In total, 496 calls were recorded, 361 of which were in the residential period (see Table 1). Fiftynine per cent of calls were from acute wards $(45 \%$ adult general and 14\% psychogeriatric), 24\% from long-stay wards, and $17 \%$ were miscellaneous. In addition, $15 \%$ of ' $A$ ' and ' $B$ ' calls came from the 'off site' community mental health unit.

Analysis by ward type showed significant falls $(P<0.05)$ in the number of ' $D$ ' calls from long-stay well staffed wards and ' $C$ ' calls from long-stay staffed wards during the non-residential period of analysis. ' $D$ ' calls from the miscellaneous group also fell $(P<0.05)$, and there was an overall reduction in ' $E$ ' calls $(P=0.023)$.

\section{Emergency calls}

There were eleven ' $A$ ' (medical emergency) calls and eleven ' $B$ ' (psychiatric emergency) calls. A delay would not have affected outcome in ten of the eleven ' $A$ ' calls. One call in which delay might have affected outcome (rated as 'possibly') was a cardiac arrest call. The patient was seen within five minutes, he was in a stable condition (breathing, with a cardiac output) and the cardiac arrest team arrived within ten minutes of the call. Nine of the eleven cases were rated as either 'definitely' or 'probably' causing no increase in distress to the patient following a delay. In one, distress was rated as 'possible', and information was not available in one case.

In all eleven ' $B$ ' cases, the doctors rated that outcome would 'definitely' or 'probably' not have been affected by a delay. In one of the psychiatric emergencies increased distress was rated as 'possible'.

\section{Inappropriate calls}

The total number of ' $D$ ' (inappropriate) calls was 121 and fell into four groups: nursing staff error, local policy, inadequate staffing levels and miscellaneous.

Nursing staff errors These included the following: not contacting the ward doctor to write up scripts; not having a patient's physical and psychiatric problems reviewed by the ward doctor when present for more than 72 hours; and contacting the duty doctor when a delay would not have resulted in unnecessary distress to the patient or risk to well-being.

Problems relating to policy These included verification of an 'expected' death: calls for completion of accident forms; calls regarding patients being absent without leave; requesting leave status be recorded in the case notes; and not accepting telephone prescriptions for minor complaints.

Inadequate staffing levels Two calls received were to check a controlled drug.

Miscellaneous GPs or Police calling about patients from different 'sectors'.

\section{Comment}

Of the large number of calls recorded, the proportion of emergency ('A' and ' $B$ ') calls was small and a delay caused by being non-resident would not have affected outcome. Although there may be occasional cases in which any delay would adversely affect outcome or increase patient distress, these are rare. On balance requiring duty doctors to be resident does not seem justified.

It could be argued that there may be reluctance by nursing staff to contact an off-site doctor. This could account for the significant fall in ' $E$ ' (advice) calls and well staffed ' $D$ ' (inappropriate) calls during the non-residential period. The fall in ' $C$ ' (urgent) calls in the 'staffed' long-stay wards may have been due to staff ensuring items were dealt with during normal working hours as there was an awareness that the duty doctor would no longer be on site outside of these.

The number of inappropriate calls could be minimised by a number of measures. Those due to nursing error could be reduced by education and feedback to the nursing staff by clinical nurse managers. It should be ensured that problems are dealt with when possible by the regular team. A review of local policies may be helpful. Verification of an 'expected' death by medical staff is not a legal requirement and non-medical staff may confirm expected deaths as is policy in some areas (Malone, 1993).

The UKGC (1992) standards for the Administration of Medicines states that "instruction by telephone to a practitioner to administer a previously unprescribed substance is not acceptable unless ... there is a specific protocol". In Newcastle, the Health Authority procedure for the prescribing of medication states that "under exceptional circumstances a telephone message 
may be accepted from a doctor by two nurses for a drug to be administered once only".

Cardiac arrests in this case were covered by the nearby general hospital, with no doctors on site. Adequate resuscitation training for all nurses is therefore essential, particularly in psychiatric hospitals without nearby cardiac arrest cover. Also, the distance from which the main hospital at which duty doctors are required to live (or maximum expected travel time) should be carefully assessed. Newcastle is fortunate in not having the severe traffic congestion problem common in many large cities. A reasonable expected attendance time for non-residential posts in the opinion of the authors is 15 minutes or less for emergencies, though up to 30 minutes would be reasonable in other cases. Inappropriate calls may be reduced by education and feedback, and review of relevant policies, including telephone prescribing and the verification of death.

\section{Acknowledgements}

We would like to thank Drs. L. Birmingham, L. Cornwall, J. Spears, Y. Marcus and R. Garner for their assistance in collecting the data, and Dr. A. Kerr for his advice in preparing the paper.

\section{References}

NHS MANAGEMENT EXEcuTtVE (1991) Junior Doctors. The New Deal. London: Department of Health.

SCHWARTZ, A. J., BLACK, E. R., GOLDSTEIN, M. G., et al (1987) Level and causes of stress among residents. Joumal of Medical Education, 62, 744-753.

LANDAU, C., HALU, S., WARTMAN, S. A. et al (1986) Stress in social and family relationships during the medical residency. Joumal of Medical Education, 61, 654-660.

Nichous. J. E. (1992) Role of the duty psychiatrist. Psychiatric Bullettr, 16, 218-219.

MALONE, D. (Northern Region Task Force Representattve) (1993) Verification of expected death. Open letter. addressed to Northern Regional Health Authortty.

UKGC. UNTED KINGDOM GENERAL COUNCR FOR NURSING Midwitery and HEAlth VIstting (1992). Portland Place. London WIN 3AF.

Andrew Lawrie, Senior Registrar in Psychiatry. Cherry Knowle Hospital, Ryhope, Sunderland SR2 ONB; "Marc A. Serfaty, Lecturer in Psychiatry, University Department of Psychiatry. Leazes Wing. Royal Victoria Infirmary, Richardson Road, Newcastle upon Tyne NE1 4LP: and Chris Smith, Regional Task Force Coordinator, NHS Executive North West, Gateway House, Piccadilly South, Manchester M66 7LP

"Correspondence 